\title{
Çin Halk Cumhuriyeti Kültür Devrimi Sürecinde Okuma Alışkanlığının Propaganda Posterlerinde Sunumu
}

\section{The Presentation of Reading Habit in the Propaganda Posters Shaped during the Chinese Culture Revolution in the People's Republic of China}

\author{
Mehmet Ali Gazi*, Caner Çakı ${ }^{* *}$, Mehmet Ozan Gülada ${ }^{* * *}$ ve Gül Çakı***
}

$\ddot{O} z$

1966-1976 yılları arasında gerçekleşen Çin Kültür Devrimi (ÇKD), Çin Halk Cumhuriyeti'nin (ÇHC) toplumsal ve kültürel yaşamında derin izler bırakmaktadır. Çin Komünist Devrimi'ne ve Mao'nun liderlik kültüne zarar vereceğine inanılan eserler tahrip edilmektedir. Kızıl Muhafizlar'ın (红卫兵) ön planda olduğu devrimde, kütüphaneler ve üniversiteler basılmakta, "eski toplumu" temsil eden yayınlar yakllmaktadır. Ülkede eski ve klasik eserler yasaklanmakta, onların yerine devrimi yücelten yayınları ön plana çıkarılmaktadır. Ayrıca Çin halkının, Başkan Mao'nun Sözleri (毛主席语录) adlı kitabı okuması teşvik edilmektedir. Devrim sırasında posterler etkili birer propaganda aracı olarak kullanılmakta ve posterler üzerinden Çin halkının neyi okuyup neyi okumamass konusunda mesajlar verilmektedir. Çalışmada propaganda posterleri üzerinden ÇHC'de ÇKD ile birlikte okuma alışkanlığının ne yönde şekillendiğinin ortaya konulması amaçlanmaktadır. Çalışmada kota örneklemi kullanılarak belirlenen 9 propaganda posteri, Fransiz dilbilimci Roland Barthes'ın kavramları özelinde göstergebilim yöntemi kullanılarak incelenmiştir. Posterlerde Çin halkının kültürel yönden bir mücadele yaşadığ anlatılmakta, bu mücadeleden de Mao ve devrimi öven yayınları okumasiyla üstün gelebileceğ belirtilmektedir Bu şekilde Mao ve devrime bağlı bireylerin oluşmasının amaçlandiğı ortaya çıkmaktadır.

Anahtar Sözcükler: Çin kültür devrimi; okuma alışkanlı̆̆g; Çin Halk Cumhuriyeti; propaganda; Mao.

\footnotetext{
* Dr. Öğr. Üyesi, Malatya Turgut Özal Üniversitesi Görsel İletişim Tasarımı Bölümü. Eposta:maligazi@gmail.com Assistant Prof. Malatya Turgut Ozal University Derpartment of Visual Comminication Design

${ }^{* *}$ Araş. Gör. İnönü Üniversitesi, İletişim Bilimleri ABD. E-posta: caner.caki@inonu.edu.tr Research Ass. Inonu University Derpartment of Communication Sciences

*** Öğretim Görv., Malatya Turgut Özal Üniversitesi Akçadağ MYO. E-posta:mehmet.guldada@ ozal.edu.tr Prelector. Malatya Turgut Ozal University Akcadağ Vocational High School

**** Bağımsız Araştırmacı, Maltepe Üniversitesi, Dr. Öğrencisi. E-posta: gulcaki06@ hotmail.com Independent Researcher, Maltepe University Ph.D Student
}

Geliş Tarihi - Received: 11.08 .2020

Kabul Tarihi - Accepted: 17.09.2020 


\section{Abstract}

The Chinese Cultural Revolution (CCR), which took place between 1966-1976, engraved in the social and cultural life of the People's Republic of China (PRC). Publications believed to harm the Chinese Communist Revolution and Mao's leadership cult were destroyed. In the revolution where the Red Guards (红卫兵) were at the forefront, libraries and universities were attacked and the publications representing the "old society" were burned. Ancient and classical works were banned in the country and publications promoting the revolution were brought to the fore. In addition, the Chinese people were encouraged to read Quotations from Chairman Mao Tsetung (毛主席语录). During the revolution, posters were used as an effective propaganda tool and messages were given on the posters about what the Chinese people should read and not. It was aimed to reveal the direction of reading habit with CCR in PRC through propaganda posters in the study. 9 propaganda posters determined using the quota sample were analyzed using the semiotics method in terms of the concepts of French linguist Roland Barthes. It was stated that the Chinese people experienced a cultural struggle and this struggle could be overcome by reading publications that praise Mao and the revolution. In this way, it was revealed that it was aimed to form individuals loyal to Mao and the revolution.

Keywords: Chinese cultural revolution; reading habit; People's Republic of China; propaganda; Mao.

\section{Giriş}

5 Ağustos 1966 tarihinde Çin Halk Cumhuriyeti (ÇHC), Çin Kültür Devrimi (ÇKD) olarak bilinen süreçte on yıllık kaos, toplumsal karışıklık ve siyasi mücadele dönemine girmektedir. Çin Komünist Partisi'nin (ÇKP) başkanı Mao Zedong tarafından başlatılan hareket, siyasi rakipleri geri plana çekmek ve 1949 Komünist Devrimi'nin güçlü ruhunu geri getirmeyi amaçlamaktadır (Powell ve Wong, 1997, s. 77). Diğer yandan devrim ÇHC'nin gelişimi üzerinde yıkıcı ve derin bir etki meydana getirmekte, ülke çapında kargaşaya, Çin okullarının ve üniversitelerinin kapatılmasına ve Çin'in kültürel ve tarihi mirasının tahrip edilmesine yol açmaktadır (Brown, 2007, s. 173). Devrim sırasında Mao'nun liderlik kültünü güçlendiren ve karş1 devrimci revisyonist gruplara karşı olan yoğun bir propaganda faaliyeti gerçekleşmektedir. $\mathrm{Bu}$ aşamada insanların tutum ve davranışlarının yönlendirilmesinde propaganda faaliyetlerinde (Avc1, 2018, s. 75) resim sanatından etkili bir şekilde yararlanılmaktadır. ÇKD'nin en kalıcı resimlerinden bazıları poster sanatlarında oluşmakta ve propaganda aracı olarak kullanılmaktadır. Posterlerdeki propaganda sanatı bir kampanya aracı ve kitle iletişim aracı olarak kullanılmakta ve çoğu zaman insanlar için önde gelen bilgi kaynağı olarak hizmet etmektedir. Çok sayıda poster üretilmekte, geniş çapta yayılmakta ve ideolojik mesajlar kitlelere posterler üzerinden ulaştırılmaktadır. Posterler kamusal alanlarda ve fabrikalarda duvarlara asılmaktadır. Propaganda amaçlı hazırlanan posterler, ÇKD için büyük öneme sahip olmaktadır. Posterler üzerinden devrime ait ideolojik mesajlar kitlelere benimsetilmeye çalışılmaktadır. Bunlardan biri de Çin halkının doğrudan okuma alışkanlığını şekillendiren ideolojik mesajlardır. Posterler yoluyla Çin halkının hangi yayınları okuması, hangi yayınlardan uzak durması anlatılmakta ve insanların devrimi yücelten yayınlara yönelmesi amaçlanmaktadır. 
ÇKD'yi ana hatlarıyla inceleyen uluslararası alanda pek çok akademik çalışma bulunmaktadır (MacFarquhar, 1974; Ahn, 1976; Lee, 1978; Dittmer, 1982; Barnouin ve Yu, 1993; Lu, 2004; Clark, 2008; Jian, 2015). Diğer yandan pek çok farklı konu özelinde de ÇKD'yi ele alan akademik çalışma mevcuttur. Gerçekleştirilen akademik çalışmaların önemli bir bölümünde ÇKD, eğitim boyutunda incelenmiştir (Swetz, 1973; Sobhe, 1982; Deng ve Treiman, 1997; Meng ve Gregory, 2002; Song, 2009; Giles vd., 2019). Diğer akademik çalışmalarda; Gittings (1966) ve Joffe (1973), ordu; Dirlik (1991), anarşizm; Gao (1994), Maocu söylem; Walder (1994) ideoloji ve politika; Zhang ve Schwartz (1997), Konfüçyüs; Roberts (2004), cinsiyet; Bryant (2005), müzik; Gao (2008), Mao; Yang ve Suchan (2009) ve Croizier (2010), sanat özelinde ÇKD'yi ele almıştır.

ÇKD'nin Çin toplumu üzerindeki etkisini inceleyen çalışmalarda; Gold (1985), Çin'de kişisel ilişkiler; Huang (1995), kırsal sınıf mücadelesi; Zang (2000), aile yaşamı; Andreas (2002), siyasi ve kültürel mücadele; Jin vd. (2006), cinsiyet ve emek konusu; Andreas (2007), kitlelerin harekete geçirilmesi; Huang (2007), çağdaş Çin edebiyatı; Han (2008), kırsal yaşamda değişim; Xu (2011), çocukların sunumu; Guoqiang ve Walder (2011), yerel politika; Perry (2018), proleter iktidarı; Berry (2004) ve McGrath (2010), Çin sineması özelinde incelemede bulunmuştur.

Çin Kültür Devrimi'ni posterler üzerinden inceleyen akademik çalışmalar da bulunmaktadır (Powell ve Wong, 1997; Benewick vd., 1999; Xing-Hua, 2005; Cushing ve Tompkins, 2007).

ÇKD ile ilgili literatür incelendiğinde, devrimi farklı konulardan ele alan çok sayıda çalışmanın olduğu ortaya çıkmaktadır. Çalışmada ÇHC'de okuma alışkanlığının ne yönde şekillendirildiği ve aynı zamanda ÇKD'de Mao'nun liderlik kültünün, okuma alışkanlığının şekillenmesinde ne yönde kullanıldığı incelenmektedir.

Çalışmada elde edilen bulgular ışı̆̆ındaki aşağıdaki sorulara yanıt aranması amaçlanmaktadır;

- Çin halkı okuma alışkanlığı bağlamında posterlerde ne şekilde sunulmaktadır?

-Posterlerde okuma alışkanlığıyla ilişkili hangi mitler (destansılaştırılan söylemler) oluşturulmaya çalışılmaktadır?

- Posterde hangi metonimilere ${ }^{1}$ yer verilmektedir?

- Mao'nun liderlik kültünün ÇHC'de okuma alışkanlığının şekillenmesindeki rolü nedir?

Çalışma, Çin'in yakın tarihine ışık tutması ve ÇKD'nin Çin'in okuma alışkanlığının şekillenmesindeki rolünü açıklaması bakımından önem taşımaktadır. Bu şekilde ideolojik kökenli devrimlerin, kitlelerin okuma alışkanlıkları üzerinde ne gibi etki bırakabileceğinin açıklanması amaçlanmaktadır.

\section{Çin Kültür Devrimi'ne Genel Bakış}

1 Ekim 1949 tarihinde Çin Halk Cumhuriyeti'nin (ÇHC) kurulmasıyla, Sovyetler Birliği (SSCB) ile birlikte dünyanın ikinci büyük komünist devleti ortaya çıkmaktadır. ÇHC'nin kurulduğu ilk yıllarda iki ülke karşılıklı olarak birbirlerini desteklemekte ve Batı Blok'u ülkelerine karşı ortak hareket etme eğiliminde olmaktadır. Buna karşılık 1953 yılında SSCB

\footnotetext{
${ }^{1}$ Metonimi, aralarında belirli bir ilişki bulunan iki kavramdan birinin diğeri yerine kullanılmasını ifade etmektedir. Bir parçanın bütünü temsilinde metonomi kavramı ön plana çıkabilmektedir (Guiraud, 2016, s. 146).
} 
Komünist Parti Genel Sekreteri Joseph Stalin'in ölümünden ve Nikita Kruşçev'in yeni Genel Sekreter olmasından sonra iki ülke arasındaki ilişkilerde gergin bir döneme girilmeye başlanmaktadır. Kruşçev'in iktidarıyla birlikte başlayan destalinizasyon süreci, ÇKP lideri Mao Zedong tarafından desteklenmemektedir. Diğer yandan Kruşçev'in Marksizm-Leninizm'in çizgisinden uzaklaştığı, Sovyetler Birliği'nde revizyonizmin gerçekleştirildiği ve MarksistLeninist temelli ülke politikasında değişikliğe gidildiği savunulmaktadır. Bu aşamada Mao, doğrudan Sovyetler Birliği'ndeki revizyonizme karşı hareket etmeye başlamaktadır. Sonuç olarak ÇKP, Çin-Sovyet ittifakının tarihinde kritik bir dönüm noktası haline gelen Moskova'yı alenen eleştirmeye karar vermektedir (Shen ve Xia, 2011, s. 862). Kruşçev 1964 y1lında istifa etse de, Çin-Sovyet çatışmaları daha da derinleşmekte ve açık düşmanlık ve askeri çatışmalara sürüklenmektedir (Li, 2011, s. 388). Çin-Sovyet ayrışması uluslararası komünist hareket içinde bölünmeye neden olmaktadır (Marku, 2020, s. 813).

Mao, Sovyetler Birliği ile yaşadığı siyasi mücadelenin dışında ülke içerisinde de kendisine karşı olaşabilecek muhalefetin önünü kesmek ve iktidarını kuvvetlendirmek için çeşitli girişimlerde bulunmaktadır. ÇHC'de muhalefetin önlenmesine yönelik çalışmalar, 1966 yılında Çin Kültür Devrimi'nin (ÇKD) başlamasına yol açmaktadır. 1966-1976 yılları arasında gerçekleşen ÇKD sırasında (Deng ve Treiman, 1997, s. 391; Jin vd., 2004, s. 544), MarksistLeninist fikirlerin ve Maoizm'in ülkede güçlenmesini sağlamak ve partiye, hükümete, orduya ve kültürel alana sızdı̆̆ı iddia edilen karşı devrimci revizyonistlerin tasfiye edilmesine çalışılmaktadır. Bütün bunlar proleter devrimi ve bürokratik ve neo-kapitalist yapılara karşı mücadele adına gerçekleşmektedir (Heberer, 2009, s. 165). Tüm bu süreçte 1966-1967 yı1ları arasında, ÇKD'nin ilk aşamasında Mao tarafından seferber edilen ve yönlendirilen kitlesel öğrenci liderliğindeki paramiliter gruplar olan Kızıl Muhafızlar (红卫兵) ön plana çıkmaktadır.

Devrim sırasında yaşanan gelişmelerde üst düzey liderler iktidardan uzaklaştırılmakta, aynı zamanda ÇKP'nin tüm ulusal bürokrasisi tamamen ortadan kaldırılmaktadır. Parti kadrosundan sorumlu, Organizasyon Departman1 (中国共产党中央委员会组织部) fiilen sona ermektedir. Kültür Devrimi Grubu (KDG), ideolojisini yaymak ve halk desteğini toplamak için öne plana çıkmaktadır. Propaganda Dairesi'nin üst düzey yetkilileri görevden alınmakta ve birçok işlevi KDG’ye devredilmektedir. 1966'dan 1969'a kadar ÇKD şiddet içinde gelişmektedir (Lester, 2005, s. 100). Ayrıca 1968 yılında Mao "Kırsal Yol Hareketi"ni başlatmaktadır. Kentli gençlerin büyük bir kısmı, devletin politikasının bir sonucu olarak kırsal bölgelere gitmek zorunda kalmaktadır (Xie vd., 2008, s. 686). Daha önce Kızıl Muhafız üyesi olan birçok öğrenci, hareketi ve Mao'nun vizyonunu desteklemiş, dolayısıyla bu hareket, kısmen Kızıl Muhafızları şehirlerden kırsal bölgelere taşımanın bir yolu halini almaktadır. $\mathrm{Bu}$ süreç, devrimci ideolojinin coğrafi olarak Çin'e yayılmasına da hizmet etmektedir.

\section{Çin Halk Cumhuriyeti'ndeki Çin Kültür Devrimi'yle Şekillenen Okuma Alışkanlığı}

Devrim, siyasetin dışında doğrudan Çin eğitim yapısı üzerinde de etkili olmaktadır. Devrim sırasında Pekin Üniversitesi yönetimine karşı başlatılan partiye karşı çıkma ve revizyonizmi ilerletme suçlamaları, Çin'deki tüm eğitim kurumlarında kalıcı bir dalgalanma etkisi oluşturmaktadır. Her yerde öğrenciler, kendi okullarının parti kuruluşlarına karşı ayaklanmaya başlamaktadır. Yaşanan bu süreç ülke çapında ilk ve ortaokullarında derslerin iptal edilmesine 
yol açmaktadır. Devrime geniş katılım, şehirlerdeki gençler için örgün eğitimin aksamasına neden olmaktadır (Lin, 2013, s. 173). Öğrencilerin, devrimi anlayabilmesi planlanmış, böylece gerek Mao'ya gerekse de rejime olan sempatinin artması amaçlanmıştır (Çakı ve Dündar, 2019, s. 21). Ayrıca Mao'nun resimlerini taşıyan ve rakiplerine karşı sloganlar atan göstericiler caddelerde ortaya çıkmaktadır. ÇKD sırasında, Mao düşüncesi, Çin'deki her şeyin merkezi etkin rehberi haline gelmektedir. Birçok üniversite öğrencisi çeşitli Kızıl Muhafız organizasyonlarına katılmaktadır (Chang, 1974, s. 187). Kızıl Muhafizlar'ın yetkisi ordunun, yerel polis yetkililerinin ve genel olarak kanunun yetkisini aşmaktadır. Çok sayıda eski bina, eser, antika, kitap ve resim Kızıl Muhafızlar tarafından tahrip edilmektedir. ÇKD'nin bir sonucu olarak Çin'deki geleneksel Çin kültürü ve kurumlarının statüsü de ciddi şekilde zarara uğramakta ve birçok geleneğin uygulaması zayıflamaktadır.

ÇKD'nin başlangıcında okullar bir süre kapalı kalmaktadır (Wang vd., 2013, s. 1001). Çin'deki kentsel bölgelerdeki tüm ilkokullar 2 ila 3 yıl süreyle kapatılmakta ve orta ve üçüncü düzey kurumlar önemli bir süre kapalı olmaktadır. Hiçbir öğretim yapılmamakta ve yeni öğrenci alınmamaktadır. Bazı okullar 1968-69 yıllarında yeniden açılmakta böylece 1966-68 yıllarında ilkokulu bitirenler liseye devam edebilmektedir ve 7-9 yaş arası çocuklar ilkokula başlamaktadır. Bununla birlikte, öğretmenlerin standart müfredatı takip etmelerine izin verilmemekte ve öğrencilerden Mao'nun düşüncesini incelemeleri ve köylülerden ve işçilerden çiftçilik ve el emeğini öğrenmeleri istenmektedir. Öğrenciler okul zamanlarının çoğunu el işi yapmak için fabrikalara ve kırlara giderek geçirmektedir (Zhang vd., 2007, s. 632).

ÇKD'de okuma alışkanlığının şekillenmesindeki en büyük eylemlerden biri Kırmızı Kitap'ın (diğer adıyla Küçük Kırmızı Kitap) ön plana çıkarılmasıdır. Devrim sırasında Çin'de okuma alışkanlığının şekillenmesinde belki de en etkili olan süreç Kırmızı Kitap'a yönelik gerçekleştirilen propaganda faaliyetleri olmaktadır. En popüler sürümler, kolayca taşınabilen ve parlak kırmızı kapaklarla ciltlenen küçük boyutlarda basılmakta ve böylece uluslararası alanda genellikle Küçük Kırmızı Kitap olarak tanınmaktadır. Asıl adıyla Başkan Mao'dan Seçme Sözler (毛主席语录) olan Kırmızı Kitap, doğrudan Mao'dan gelen alıntıları içermektedir. Mao, devrimi, "revizyonistler" ve "kapitalistler" tarafından tehdit edildiğine inandığı komünizmin ideolojik saflığını yeniden kurmak ve buna göre Mao Zedong Düşüncesi'ni yeniden oluşturmak için kullanmak istemektedir (Zhouxiang, 2016, s. 569). Bu açıdan Kırmızı Kitap Mao'nun kitlelere düşüncelerini aktarmasında önemli bir araç olmaktadır. Milyonlarca kopya basılan kitabın Çin halkı tarafından okunması ve içinde barındırdığı ilkelerin Çin halkının yaşamında rehber olarak kullanılması amaçlanmaktadır. ÇKP'nin propaganda sanatçıları tarafından oluşturulan afiş ve resimlerde, gülümseyen ya da kararlı görünen pek çok karakter, elinde kitabın bir kopyasıyla ön plana çıkarılmaktadır. Devrimin sona ermesinden sonra kitabın önemi önemli ölçüde azalmakta ve Mao'nun alıntılarının yüceltilmesi, liderlik kültü olarak değerlendirilmektedir.

Devrim, parti içinde, hükümette, orduda, entelektüeller arasında burjuva fikirlerini savunanları etkisiz hale getirmeye çalışmaktadır. Ayrıca Kızıl Muhafız mitinglerinde dört eski'nin yok edilmesi çağrısında bulunulmaktadır; yani eski adetler, kültürler, alışkanlıklar ve fikirler (Xiuyuan, 1994, s. 534). "Dört Eski" kampanyası kapsamında şehir sokaklarına ve yerlere yeni adlar verilmektedir. Kızıl Muhafız faaliyetlerinin diğer yönleri, özellikle kültür alanlarında daha sert olmaktadır. Ülke genelinde çeşitli tarihi yerler tahrip edilmektedir. Tarihi 
ve yabancı metinlerle dolu kütüphaneler yok edilmekte, kitaplar yakılmaktadır. ÇKD, eğitim kurumlarına yaptığı gibi, Çin kütüphanelerine neredeyse onarılamaz zararlar vermektedir (Ting, 1981, s. 430). İnsanların eski alışanlıklarından uzaklaşması istenmekte, Mao'nun düşüncelerinin egemen olduğu yeni bir Çin toplumunun oluşmasına çalışılmaktadır. Bu aşamada Kırmızı Kitap, Çin halkının okuması gereken temel eser olarak sunulmaktadır.

Devrim sırasında Mao ve sosyalizm karşıtı yayınlar sert bir şekilde eleştirilmektedir. Ayrıca eski kültür'ün alıcıları ve yayıcıları olan yazarlar, sanatçılar ve entelektüeller kapsamlı bir şekilde geri plana çekilmektedir. Ülkede Mao'ya ve devrime karşı muhalif olabilecek her türlü yayın yasaklanmakta ve tehdit olarak sunulan bu yayınların insanlar tarafindan okunmasının önüne geçilmeye çalışılmaktadır. Yüzyıllar boyunca öğretim materyali olarak kullanılan Konfüçyüs klasikleri de dahil olmak üzere eski Çin metinleri, dört eski'ye ait oldukları için hedef haline gelmektedir (Leung ve Wang, 2012, s. 51). Bu kitaplara alternatif olarak doğrudan Kırmızı Kitap ve Marksist-Leninist öğretiler içeren kitapların okunması teşvik edilmektedir. Bu yönünle devrim, Çin halkının okuma alışkanlığı üzerinde etkili olmakta ve onların neyi okuyup neyi okumaması gerektiği konusunda doğrudan müdahalede bulunabilmektedir. İnsanların devrimi yücelten ve Mao'nun düşüncelerinin ve liderlik kültünün güçlenmesini sağlayacak eserleri okuması istenmektedir. Mao'nun düşüncelerinin okunması teşvik edilerek, Çin halkının Mao'nun düşüncelerinden dışarı çıkmaması amaçlanmaktadır. Özellikle Sovyetler Birliği'nde yaşanan revizyonist dalganın Çin'e ulaşmasının önüne geçilmeye çalışılmakta, bu açıdan karşı devrimci revizyonist yayınların Çin halkı tarafından okunmasına karşı çıkılmaktadır. Çin halkının, Sovyetler Birliği'ndeki revizyonist etkiden korunması için yine Kırmızı Kitap'ın okunması teşvik edilmektedir.

Kırmızı Kitap'ın Çin halkı tarafından okunmasının teşvik edilmesi ile okuma alışkanlığı arasında doğrudan ilişki kurulamayabilinir. Buna karşılık Çin halkının hem kitap okuması teşvik edilmekte hem de ne okuması gerektiği konusunda söylemde bulunulmaktadır. Çin'de gelecek nesillerin Kırmızı Kitap'ı hayatlarının önemli bir parçası olarak algılamalarına, Kırmızı Kitap'ın rehberliğinde daha müreffeh bir yaşama kavuşacaklarına inanmalarına çalışılmaktadır. Bu süreç Çin halkının Kırmızı Kitap'da yer alan söylemleri günlük hayatlarında uygulamalarına ve Kırmızı Kitap'a muhalif olan kitaplardan uzak durmalarına neden olabilmektedir. Bu şekilde Kırmızı Kitap ve devrimi yücelten kitapların okunması teşvik edilerek dolaylı olarak Çin halkının okuma alışkanlığı kazanmasında etki oluşturulduğu söylenebilmektedir.

\section{Yöntem}

ÇKD sırasında okuma alışkanlığı üzerinde etkili olan tüm propaganda posterleri çalışmanın evrenini oluşturmaktadır. Nitekim posterler ÇKD'nin propaganda faaliyetlerinde etkili bir şekilde kullandığı kitle iletişim araçlarından biri olarak ön plana çıkmaktadır (Arıca, 2019, s. 394; Karaca vd., 2020, s. 1143). Çalışmada gerçekleştirilen kapsamlı araştırma sonucunda konuyu ele alan 30 propaganda posterine Şanghay Propaganda Posterleri Sanat Müzesi'nden ulaşılmaktadır (IISH, 2020). 30 propaganda posteri içerisinden kota örneklemi kullanılarak belirlenen 8 propaganda posteri çalışmanın örneklemi olarak seçilmiştir. Örneklem olarak belirlenen propaganda posterleri, nitel araştırma yöntemleri içerisinde yer alan göstergebilim yöntemi kullanılarak analiz edilmektedir. ÇHC'de propaganda posterleri üzerinden inşa edilmek 
istenen alg1, Fransız dilbilimci Roland Barthes'ın göstergebilim anlayışı çerçevesinde incelenmektedir.

Göstergebilim, göstergeleri inceleyen (Guiraud, 2016, s. 17) ve 20. yüzyılda popüler olan bir bilim dalıdır (Gülada, 2019, s. 1086). Gösterge ise bir kavramın başka bir kavramı tanıtmak veya temsil etmek amacıyla kullanılmasıdır (Rifat, 2013, s. 97). Göstergebilim alanındaki çalışmalar 20. yüzyılın ilk yarısında ortaya çıkmakta ve göstergebilim, ikinci yarısında da sosyal bilimler alanında önemli bir yöntem haline gelmektedir. Göstergebilim, dilbilimciler Ferdinand de Saussure ve Charles Sanders Peirce'in çalışmalarıyla bilim haline gelmektedir. Barthes, göstergebilim çalışmalarında Saussure'ün etkisinde kalmakta ve Saussure'ün gösteren ${ }^{2}$ ve gösterilen ${ }^{3}$ kavramlarını Anlamlandırma Modeli'ne eklemektedir. Barthes, her iki kavramın yanında göstergebilimi açıklarken düz anlam ${ }^{4}$, yan anlam ${ }^{5}$ ve mit ${ }^{6}$ kavramlarına da atıfta bulunmaktadır (Şekil 1). Barthes'ın kuramında düz anlam ve yan anlam olmak üzere anlamlandırmanın iki boyutu olmaktadır (Kalkan Kocabay, 2008, s. 34; Sığırcı, 2016, s. 73). Barthes, yan anlamların kültürlere özgü olduğunu açıklamakta, bu nedenle yan anlamların kültürden kültüre farklılaşabileceğini belirtmektedir. Benzer şekilde mitlerin de kültüre özgü olduğunu ve kültür içerisinde oluştuğunu ileri sürmektedir. Topluma egemen olan gücün mitlerin oluşmasında etkili olduğu savunulmaktadır. Barthes, kültürel olanın doğallaştığı bir sürecin olduğunu belirtmektedir (Barthes, 2017, s. 18). Diğer bir deyişle toplum içerisinde egemen güç tarafından oluşturulan mitler üzerinden neyin doğru neyin yanlış, kimin dost kimin düşman olduğu belirlenmektedir. Barthes, pek çok şeyde iktidarın varlığının hissedildiğini açıklamaktadır (Barthes, 2015, s. 45). Bu aşamada medyanın kontrolünü elinde bulunduran egemen güçler, ideolojik söylemlerini kitle iletişim araçları yoluyla toplumda hakim kılmaya çalışabilmektedir.

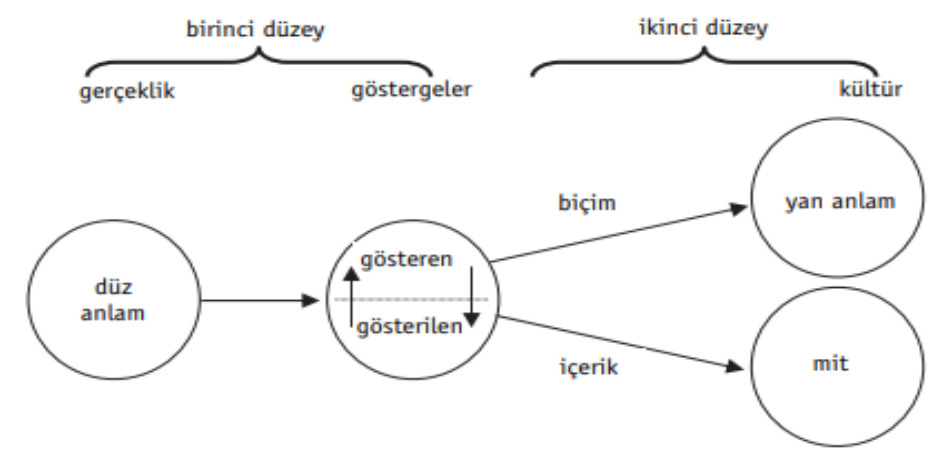

Şekil 1. Roland Barthes'in Anlamlandırma Modeli (Kaynak: Fiske, 2017, s. 186).

\footnotetext{
${ }^{2}$ Gösteren (signifier), bir kavramın herkes tarafından kabul gören ilk anlamını ifade etmektedir (Kalkan Kocabay, 2008, s.16).

${ }^{3}$ Gösterilen (signified), bir kavramın uzlaşı sonucunda ortaya çıkan ilk anlamının dışındaki ikinci anlamı açıklamaktadır (Kalkan Kocabay, 2008, s. 16).

${ }^{4}$ Düz anlam (denotration), göstergenin algılanan ilk anlamını tanımlamaktadır (Sı̆̆ırcı, 2016, s. 73).

${ }^{5}$ Yan Anlam (connotation), kavramların kültürden kültüre değişen, diğer bir deyişle kültüre özgü anlamlarını tanımlamaktadır (Sı̆̆ırcı, 2016, s. 74).

${ }^{6}$ Mit, kültürlerin çevresinde yaşanan olayları açıklama çabasının ürünü olan düşünceleri tanımlamaktadır (Fiske, 2017, s. 185).
} 
Çalışma kapsamında ÇHC'de propaganda posterleri üzerinden Çin toplumunda okuma alışkanlığının şekillenmesinde hangi mesajların verildiği ve hangi algıların oluşturulduğu Anlamlandırma Modeli üzerinden ele alınmaktadır. Bu açıdan çalışmada örneklem olarak belirlenen propaganda posterleri ilk olarak düz anlam kavramı üzerinden ele alınmakta, daha sonra yan anlam ve mit kavramları ${ }^{7}$ ş̧ı̆ıında analiz edilmektedir. Elde edilen bulgular 1şı̆̆ında ÇHC'de ÇKD'nin okuma alışkanlığı üzerindeki etkisi ortaya konulmaya çalışılmaktadır.

\section{Bulgular ve Yorum}

Çalışmanın bu kısmında "Kızıl Bayrak", "Köylüler", "Kızıl Çiçekler", "Mücadele", "Kitleler", "Geçmiş", "Çobanlar", "Mao" ve "Tarih" konulu propaganda posterleri göstergebilimsel açıdan analiz edilmektedir.

\section{"Kızll Bayrak" Konulu Propaganda Posteri}

1967 y1lına tarihlenen "Kizıl Bayrak" konulu propaganda posterinin kim tarafindan hazırlandığına yönelik bilgiye ulaşılamamaktadır. Düz anlam boyutunda ele alındığında posterin merkezinde devasa boyutta resmedilen biri kadın üç kişi görülmektedir. Posterde yer alan erkeklerden birinin üzerinde asker üniforması, diğerinin üzerinde ise işçi tulumu bulunmaktadır. Resmedilen üç kişinin de elinde birer kitap olduğu görülmekte, asker üniforması içerisindeki kişinin elindeki kitabı havaya kaldırdığı yansıtılmaktadır. Üç kişinin önünde biri yere düşmüş ve biri yerde bulunan iki kişi ve çevrelerinde kitapların olduğu resmedilmektedir. İşçi tulumu giyen kişinin yumruğuyla, kadının ise sağ işaret parmağıyla önündeki iki kişiyi ve yayınları hedef aldığı aktarılmaktadır. Posterin fonunda kırmızı renk kullanılmakta, görsel kodlar içerisinde de posterde yer alan kişiler kararlı bir duruşla sunulmaktadır.

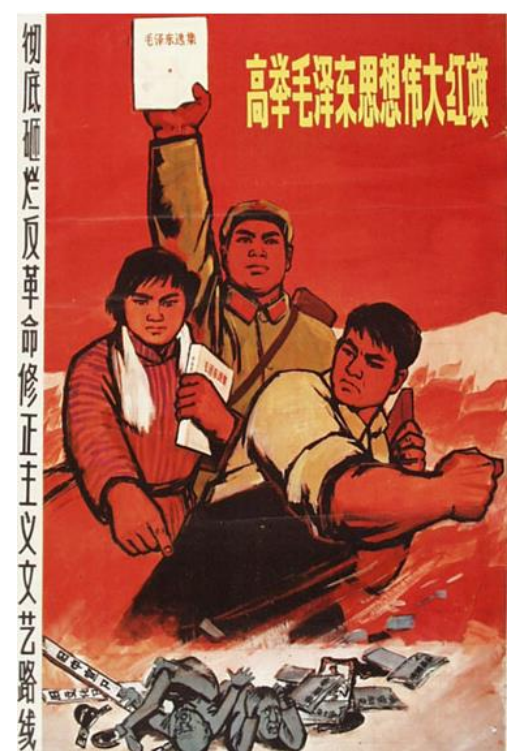

Poster 1. "Kızıl Bayrak" Konulu Propaganda Posteri ${ }^{8}$ (Kaynak: IISH, 2020).

\footnotetext{
${ }^{7}$ Barthes’’n mit kavramı çalışma kapsamında destansallaştırılan söylem olarak ele alınmaktadır.

${ }^{8}$ Posterde "Mao Zedong Düşüncesinin büyük kırmızı bayrağını yüksek tutun - karşıdevrimci revizyonist edebiyat ve sanat çizgisini tamamen parçalayın (高举高举毛泽东思想伟大红旗 - 彻底砸烂反革命修正主义文艺路线)" yazmaktadır.
} 
Tablo 1

"Kizll Bayrak" konulu propaganda posteri

\begin{tabular}{cc}
\hline \multicolumn{1}{c}{ Düz anlam } & İnsanların mücadelesi \\
\hline Gösteren & İnsanlar \\
\hline Gösterilen & Mücadele \\
\hline Yan anlam & Çin halkının karşı devrimci revizyonist yayınları okumaması \\
Metonimi & Çinli siviller ve Çin askeri \\
\hline Destansallaştırılan & Mao ve politikalarına karşı yayınların okunması, devrime \\
Söylem & zarar verir \\
\hline
\end{tabular}

Yan anlam açısından incelendiğinde posterde yer alan kişilerin giydikleri kıyafetlerden Çin halkının, yerde bulunan kişilerin de posterdeki yazılı kodlardan Mao'ya ve devrime muhalif unsurların metonimi oldukları ortaya konulmaktadır. Posterde asker üniforması giyen kişi Çin ordusunun, yerel kıyafetler içerisindeki kadın Çinli sivillerin ve işçi tulumu içerisindeki erkek de Çin'de çalışan sınıfın metonimi olarak ön plana çıkarılmaktadır. Diğer yandan posterdeki Çin halkının metonimi olarak kullanılan kişilerin, diğer iki kişiye göre devasa gösterilmesi Mao taraftarlarının Mao muhaliflerine karşı çok daha güçlü olduğu algısını oluşturmaktadır. $\mathrm{Bu}$ şekilde Mao'nun politikalarının geniş kitleler tarafından desteklendiği mesajı verilmektedir. Posterin fonunun kırmızı renkte olması, Çin'deki Çan Kay Şek liderliğindeki milliyetçi güçlere karşı kazanılan kızıl devrimi simgelemektedir. Posterde yer alan her üç kişinin de elinde tuttuğu kitabın Başkan Mao'nun Sözleri adlı kitap olduğu algısı oluşturulmaktadır. Çin halkını temsil eden üç kişinin elinde Başkan Mao'nun Sözleri adlı kitabı tutması ve Mao'ya ve devrime muhalif olarak nitelendirilen yayın ve kişilere karşı davranışları ile Mao ve politikalarına karşı her türlü yayına kitlelerin karşı çıktığı mesajı verilmektedir. Devrimin varlığını sürdürebilmesi için de insanların Mao ve devrimi destekleyen yayınları okuması teşvik edilmektedir. Posterdeki yazılı göstergeler de doğrudan Mao ve devrime karşı olan kitaplara yönelik nefret söylemine yönelmekte ve bu tür kitapların okunmasının bir suç olarak algılanmasına yol açılmaktadır. $\mathrm{Bu}$ açıdan posterdeki görsel ve yazılı kodlar "Mao ve politikalarına karşı yayınların okunması, devrime zarar verir" şeklinde destansılaştırılan söylemin oluşmasına zemin hazırlamaktadır. Posterdeki görsel göstergeler doğrudan ÇKD sırasında Mao ve politikalarına karşı olan ve zararlı olarak nitelendirilen kitapların yok edilmesini teşvik edici nitelik taşımaktadır.

\section{"Köylüler" Konulu Propaganda Posteri}

1969 yılında hazırlanan "Köylüler" konulu propaganda posteri, Sichuan Sanat Akademisi Devrimci Komitesi (四川美术学院革命委员会供稿) tarafindan yapılmaktadır. Düz anlam açısından incelendiğinde posterin merkezinde bir kız çocuğu, bir erkek çocuğu ve bir yetişkin erkeğin resmedildiği görülmektedir. Posterde yer alan her üç kişinin de güldüğü ve Mao'nun resmi bulunan rozetler taktığı aktarılmaktadır. Yetişkin erkek ile erkek çocuğun ellerinde 
kitapların bulunduğu yansıtılmaktadır. Posterin fonunda nehir, dağ ve güneş görselinin yanında, Mao'nun resmini taşıyan kitleler resmedilmektedir.

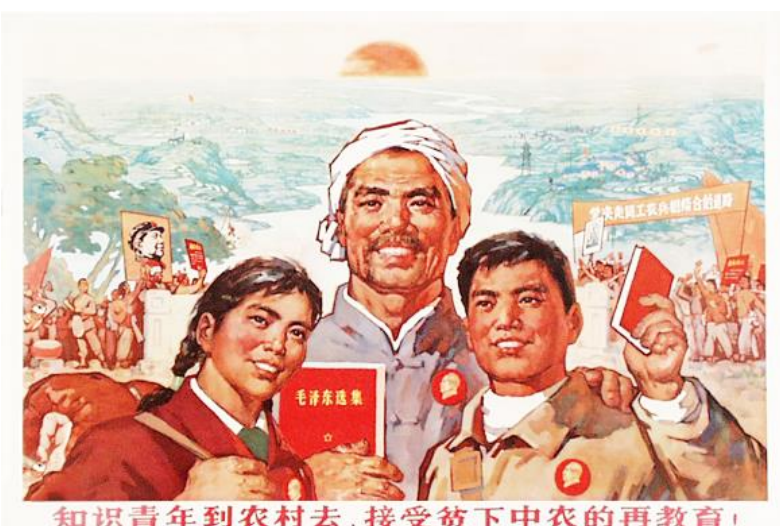

Poster 2. "Köylüler" Konulu Propaganda Posteri' (Kaynak: IISH, 2020).

Tablo 2

"Köylüler" konulu propaganda posteri Düz anlam Köylü ve gençlerin kitap tutması

\begin{tabular}{|cc|}
\hline Gösteren & İnsan \\
\hline Gösterilen & Maoizm \\
\hline Yan anlam & İnsanların Mao'nun düşüncelerini okuduğu \\
\hline Metonimi & Çinli köylü ve öğrenciler \\
\hline $\begin{array}{c}\text { Destansallaştırlan } \\
\text { Söylem }\end{array}$ & Çin halkı, Mao'nun düşüncelerini öğrenmeyi sever \\
\hline
\end{tabular}

Yan anlam boyutunda ele alındığında posterde yer alan iki çocuğun Çinli öğrencilerin, yetişkin kişinin ise Çin'de kırsal alanda yaşayan Çinlilerin metonimi olarak kullanıldığı ortaya çıkmaktadır. Posterde ÇKP'nin Çinli gençleri dağlara ve köylere gönderdiği programların konu edinildiği anlaşılmaktadır. Programlar kapsamında Çin'de eğitim alan gençlerin köylere gitmesi teşvik edilmekte ve gittikleri köylülerde yaşayanlar ile bilgi alışverişinin sağlanması amaçlanmaktadır. Bu şekilde Çinli köylülerin, Çinli gençlerin eğitim ve bilgisinden yararlanması, Çinli gençlerin de kırsal alanlarda yaşamasının teşvik edilmesi hedeflenmektedir. Posterde her üç kişinin de elinde Kırmızı Kitap'ı tutması ve göğüslerinin üzerinde Mao'nun resminin bulunduğu rozetleri takmaları, doğrudan Çin halkının Mao'nun düşüncelerini benimsediği mesajını vermektedir. Diğer yandan posterin arka planında kitlelerin Mao'nun resmini taşıması da benzer şekilde Mao'nun kült liderliğini güçlendirmektedir. Posterde yer alan tüm bu görsel göstergeler "Çin halkı, Mao'nun düşüncelerini öğrenmeyi sever" şeklindeki destansılaştırılan söylemin oluşmasına yol açmaktadır. Posterde ülke genelinde insanların

\footnotetext{
${ }^{9}$ Posterde "Eğitimli gençler, Yoksul ve Aşağı-Orta köylülerden yeniden eğitim almak için kırsal bölgeye gitmelidir! (知识青年到农村去, 接受贫下中农的再教育!)" yazmaktadır.
} 
Mao'nun düşüncelerini ve devrimi yücelten kitapları okuduğuna yönelik genel bir alg1 oluşturulmakta ve bu şekilde Mao'ya ve devrime muhalif yayınların marjinalleştirilerek etkisiz hale getirilmesi amaçlanmaktadır. Hem eğitim alarak köylere giden gençlerin hem de köylülerin Mao ve devrimi öven yayınları okumaları, Mao ve devrim karşıtı kitaplardan uzak durmaları hedeflenmektedir. Genel çerçevede Mao ve devrimi öven kitapları okuyan Çinliler toplum genelinde ideal bireyler olarak sunulmaktadır.

\section{"Kızll Çiçekler" Konulu Propaganda Posteri}

Shanxi Eyaleti Devrimci Komitesi Siyasi Çalışma Grubu'nun Kültür ve Eğitim Ofisi'nin katkılarıyla hazırlanan "Kızıl Çiçekler" konulu propaganda posteri, 1970'li yılların başları olarak tarihlenmektedir. Düz anlam boyutunda ele alındığında posterde Mao'nun resmi altında ellerinde kırmızı kitap bulunan, farklı kültürlere ait kıyafetler giyen insanların resmedildiği görülmektedir. Görsel göstergelerde posterde yer alan kişilerin gülümsedikleri yansıtılmaktadır. Posterin kırmızı renkteki fonunda da dağ, tarla ve kırmızı bayraklar taşıyan kitleler resmedilmektedir.

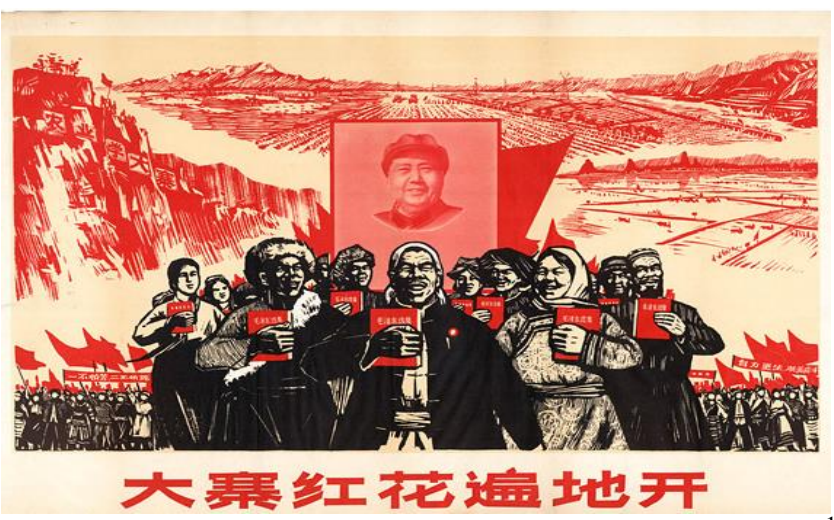

Poster 3. "Kızıl Çiçekler" Konulu Propaganda Posteri ${ }^{10}$ (Kaynak: IISH, 2020).

Tablo 3

"Kızıl Çiçekler" konulu propaganda posteri
Düz anlam
Ellerinde kitap olan insanlar

\begin{tabular}{cc}
\hline Gösteren & İnsan \\
\hline Gösterilen & Maoizm \\
\hline Yan anlam & Mao'nun düşüncelerinin okunmasının huzur getireceği \\
\hline Metonimi & Çin'deki farklı etnik gruplar \\
\hline $\begin{array}{c}\text { Destansallaştırılan } \\
\text { Söylem }\end{array}$ & Tarım işçileri de, Mao'nun düşüncelerini benimser \\
\hline
\end{tabular}

Yan anlam açısından incelendiğinde posterde Dazhai tarım bölgesinin konu edinildiği görülmektedir. Dazhai, 1960'lı ve 1970'li yıllarda ÇKD boyunca Çin'in her yerinde tarımsal üretim modeli olarak belirlenmektedir. Bu açıdan bölge, Çin'in tarımsal üretimin simgesi haline gelmektedir.

\footnotetext{
${ }^{10}$ Posterde "Dazhai kızıl çiçekler her yerde çiçek açar (大寨红花遍地开)" yazmaktadır.
} 
Posterde farklı kültürlere ait kıyafetler giyen insanlar, Çin'de yaşayan ve tarım üretiminde çalışan farklı etnik grupların ve kültürlerin metonimi olarak kullanılmaktadır. Posterde Çin nüfusunun önemli bir bölümünü oluşturan ve devrimin gerçekleşmesinde önemli bir güç olan tarım işçilerinin konu edinildiği ortaya çıkmaktadır. Arka planda yer alan ve güç metaforu olarak sunulan Mao resmi de kitlelerin Mao'nun izinden gittiği mesajını vermektedir. Posterin fonun kırmızı renkte olması ve insanların kırmızı bayraklar taşıması, Çin Komünist Devrimi'ne ve Komünizm ideolojisine atıfta bulunmaktadır. İnsanların Kırmızı Kitap ' 1 taşımaları ve gülümsemeleri, yine Mao ve düşüncelerinin kitleler tarafından benimsediği algısını oluşturmaktadır. Bu şekilde "Tarım işçileri de, Mao'nun düşüncelerini benimser" şeklindeki destansılaştırılan söylemin benimsetilmesine çalışılmaktadır. Böylece toplum genelinde Mao'nun düşüncelerinin hakim olduğuna yönelik alg1 oluşturulmakta, komünist devrim ve Mao'nun düşünceleri bütünleştirilmekte, nihayetinde tarım işçilerinin de yalnızca Mao ve devrimi yücelten yayınları okumasının sağlanması amaçlanmaktadır.

\section{"Mücadele" Konulu Propaganda Posteri}

1970'li yılların başları olarak tarihlenen "Mücadele" konulu propaganda posterinin kim tarafından hazırlandığı bilinmemektedir. Düz anlam açısından incelendiğinde posterde bir masanın etrafında biri kadın iki yetişkin kişi ve dokuz çocuk resmedilmektedir. Posterde yerde bir kaç kitabın bulunduğu, bir çocuğunda bir kitabı önündeki sepete attığı aktarılmaktadır. Görsel göstergelerde çocukların yerdeki ve sepetteki kitaplara öfkeli bir şekilde baktığı yansıtılmaktadır.

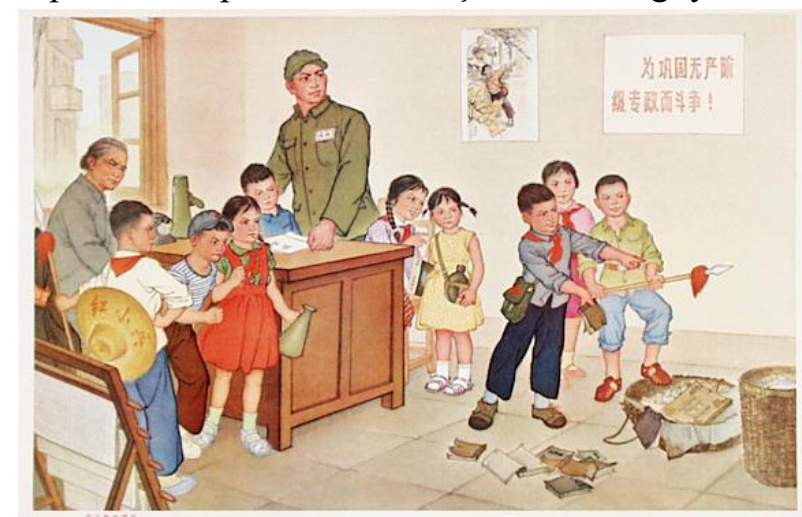

Poster 4. "Mücadele" Konulu Propaganda Posteri" ${ }^{11}$ (Kaynak: IISH, 2020).

Tablo 4

"Mücadele" konulu propaganda posteri

\begin{tabular}{cc}
\hline Düz anlam & Kitapların atılması \\
\hline Gösteren & İnsan \\
\hline Gösterilen & Mücadele \\
\hline Yan anlam & Çin halkının devrim karşıtı yayınlarla mücadele etmesi \\
\hline Metonimi & Çinli çocuklar \\
\hline Destansallaştırılan & Çinli çocuklar, Mao ve devrime muhalif yayınları okumaz \\
\hline Söylem & \\
\hline
\end{tabular}

\footnotetext{
${ }^{11}$ Posterde "Mücadelenin ortasında büyümek (在斗争中成长)" yazmaktadır.
} 
Yan anlam boyutunda ele alındığında posterde Çinli öğrencilerin Mao ve devrime muhalif yayınları ortadan kaldırdığı aktarılmaktadır. Posterde yer alan çocuklar, Çinli çocukların, posterde yer alan yetişkinler ise Mao'nun düşüncelerini destekleyen kişilerin metonimi olarak kullanılmaktadır. Posterde yerde ve sepette bulunan kitaplar, Mao ve devrimlerine muhalif kitapları simgelemektedir. Mao ve devrimine muhalif yayınları ortadan kaldıran çocuklar, idealize edilmiş Çinli bireyler olarak sunulmaktadır. Bu şekilde "Çinli çocuklar, Mao ve devrime muhalif yayınları okumaz" şeklindeki destansılaştırılan söylemin hakim kılınması amaçlanmaktadır. Posterde Mao ve devrime muhalif kitaplar, zararlı ve tehlikeli olarak sunulmakta ve çocuklar da dahil olmak üzere herkesin karşı devrimcilere yönelik mücadele etmesi gerektiği mesajı verilmektedir. Posterdeki yazılı göstergelerde de karşı devrimcilerin yayınlarının ortadan kaldırılması mücadele olarak vurgulanmaktadır. Bu şekilde karşı devrimci yayınların ortadan kaldırılması teşvik edilmekte ve genç nesillerin Mao ve devrime muhalif yayınlardan uzak durması amaçlanmaktadır.

\section{"Kitleler" Konulu Propaganda Posteri}

1971 yılında hazırlanan "Kitleler" konulu propaganda posteri, Tianjin Sanayi Sergi Salonu Devrim Komitesi (天津市工业展览馆革命委员会) tarafindan yapılmaktadır. Düz anlam boyutunda ele alındığında posterin merkezinde üzerinde Mao'nun resmi bulunan, işçi tutumları içerisinde bir erkek görselinin olduğu görülmektedir. Posterdeki kişinin bir elinde bir kalem diğer elinde ise bir kitap bulunmaktadır. Posterin ön kısmında kırmızı bayraklar taşıan bir grup insan resmedilmektedir. Posterin arka planında ise fabrika görseli ve gökyüzüne doğru çıkan bir duman bulutu aktarılmaktadır.

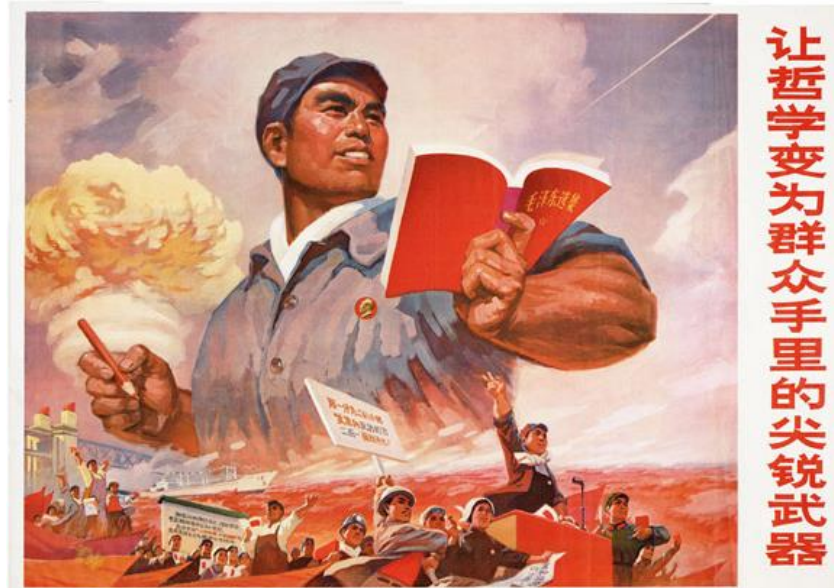

Poster 5. "Kitleler" Konulu Propaganda Posteri ${ }^{12}$ (Kaynak: IISH, 2020).

\footnotetext{
${ }^{12}$ Posterde "Felsefeyi kitlelerin elinde keskin bir silaha dönüştürün (让哲学变为群众手里的尖锐武器) yazmaktadir.
} 
Çin Halk Cumhuriyeti Kültür Devrimi Sürecinde Okuma Alışkanlığının Propaganda Posterlerinde Sunumu The Presentation of Reading Habit in the Propaganda Posters Shaped during the Chinese Culture Revolution in the People's Republic of China

Tablo 5

"Kitleler" konulu propaganda posteri

\begin{tabular}{cc}
\hline Düz anlam & Duman bulutunun önünde işçinin durması \\
\hline Gösteren & İnsan \\
\hline Gösterilen & Maoizm \\
\hline Yan anlam & Mao'nun düşüncelerinin okunmasının Çin halkını güçlendireceği \\
& düşüncesi \\
\hline Metonimi & İşçi \\
\hline $\begin{array}{c}\text { Destansallaştırılan } \\
\text { Söylem }\end{array}$ & Mao ve politikasını öğrenmek, Çin toplumunu güçlü kılar \\
\hline
\end{tabular}

Yan anlam açısından incelendiğinde posterde Kırmızı Kitap'ı elinde tutan ve göğsünde Mao'nun resmi olan rozet taşıyan işçinin, Çin'deki çalışan sınıfın metonimi olduğu yansıtılmaktadır. Posterin önünde yer alan kitleler de benzer şekilde Çin'deki çalışan sınıfı temsil etmektedir. Görsel kodlar içerisinde işçinin Kırmızı Kitap'ı okuması ile devasa boyutta gösterilmesi arasında bir ilişkiselliğin oluşturulması amaçlanmaktadır. Diğer yandan posterin arka planında güç metaforu olarak sunulan bulut da, Mao'nun Kırmızı Kitap'ının okunmasının Çin halkını güçlü kılacağı algısını oluşturmaktadır. Bu şekilde "Mao ve politikasını öğrenmek, Çin toplumunu güçlü kılar" şeklindeki destansılaştırılan söylemin hakim kılınmasına çalışılmaktadır. Posterde güçlü bir Çin için insanların Mao ve devrimi yücelten yayınları okunması teşvik edilmektedir.

\section{"Geçmiş" Konulu Propaganda Posteri}

1975 yılına tarihlenen "Geçmiş" konulu propaganda posterinin kim tarafindan hazırlandığına dair bilgiye ulaşılamamaktadır. Düz anlam açısından incelendiğinde posterin merkezinde işçi tulumu içerisinde bir adamın resmedildiği görülmektedir. Posterdeki adamın önünde iki mikrofon ve bir kaç kitabın olduğu resmedilmektedir. Posterin arka planında diğer işçilerin olduğu, posterin fonunda ise işçilerin bulunduğu alanın bir fabrika olduğu yansıtılmaktadır.

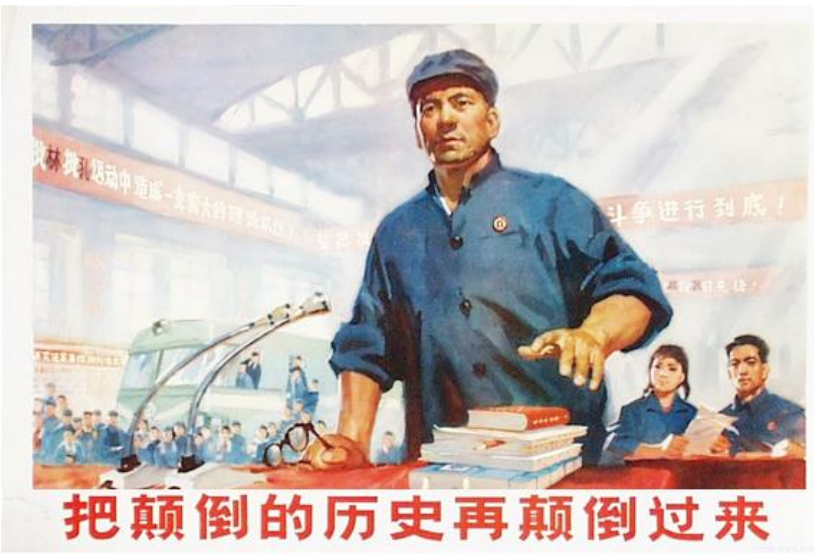

Poster 6. "Geçmiş" Konulu Propaganda Posteri ${ }^{13}$ (Kaynak: IISH, 2020).

\footnotetext{
${ }^{13}$ Posterde "Tersine çevrilmiş geçmişi baş aşağı çevirin (把颠倒的历史再颠倒过来)" yazmaktadır.
} 
Tablo 6

"Geçmiş" konulu propaganda posteri

Düz anlam İşçinin mikrofonun önünde olması

\begin{tabular}{|cc|}
\hline Gösteren & İnsan \\
\hline Gösterilen & Maoizm \\
\hline Yan anlam & Çin halkının devrim yanlısı kitaplar okuması \\
\hline Metonimi & İşçiler \\
\hline $\begin{array}{c}\text { Destansallaştırılan } \\
\text { Söylem }\end{array}$ & Çin toplumu, eski alışkanlıkları terk etmektedir \\
\hline
\end{tabular}

Yan anlam boyutunda ele alındığında posterde fabrikada çalışan işçilerin Mao ve devrimi yücelten kitaplar okuduğuna yönelik algı oluşturulmaya çalışıldığı ortaya çıkmaktadır. Posterde resmedilen işçiler, Çin'de ağır sanayide çalışan işçilerin metonimi olarak kullanılmaktadır. Çalışma kapsamında incelenen diğer posterlerde görüldüğü gibi Çin toplumunun farklı grupları içerisinde Mao ve devrimi yücelten yayınların okunduğu aktarılmakta, bu şekilde ülke genelinde Mao'nun düşüncelerinin hakim olduğuna yönelik mesaj verilmektedir. Posterde yer alan Kırmızı Kitap üzerinden Çin'de işçi sınıfının benzer şekilde Mao'nun düşüncelerini izlediği iddia edilmektedir. Posterdeki yazılı gösterge ise posterde verilen propaganda mesajını farklı bir noktaya taşımaktadır. Yazılı gösterge üzerinden ÇKD'de karşı çıkılan "eski toplum" olgusu eleştirilmekte ve Çin toplumun eski alışkanlıkları terk ederek Mao'nun düşünceleri çerçevesinde hareket etmesi gerektiği vurgulanmaktadır. Posterde "Çin toplumu, eski alışkanlıkları terk etmektedir" şeklindeki destansallaştırılan söylem kullanılmaktadır. Böylece insanların "eski toplum"u savunan yayınların yerine Mao'yu ve devrimi yücelten yayınları okumaları teşvik edilmektedir.

\section{"Çobanlar" Konulu Propaganda Posteri}

1976 yılında hazırlanan "Çobanlar" konulu propaganda posteri, Shao Hua ve Shao Qinglin tarafindan yapılmaktadır. Düz anlam boyutunda ele alındığında posterde yerel kıyafetler içerisindeki bir grup insanın kitapçıdan (veya kütüphaneden) kitap aldıkları resmedilmektedir. Görsel kodlarda posterdeki kişiler mutlu olarak yansıtılmaktadır. 


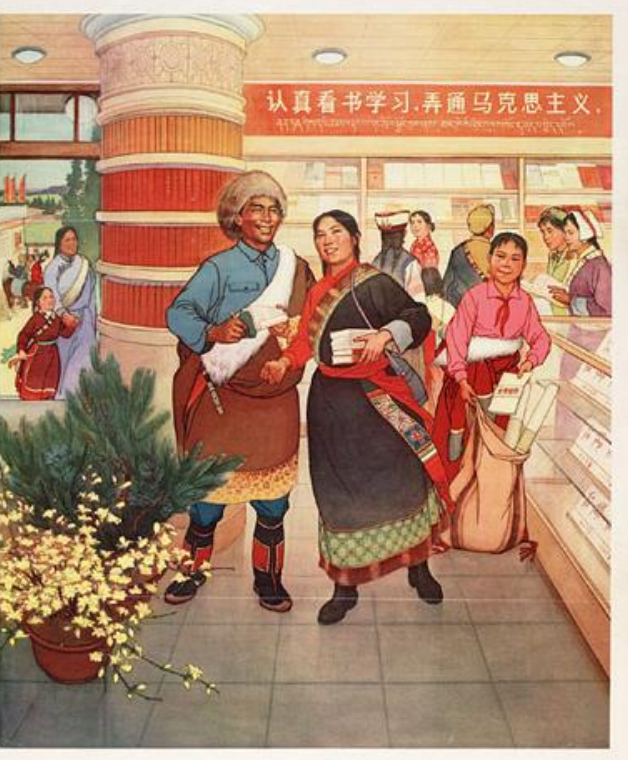

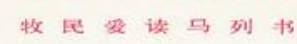

Poster 7. "Çobanlar" Konulu Propaganda Posteri ${ }^{14}$ (Kaynak: IISH, 2020).

Tablo 7

"Çobanlar" konulu propaganda posteri

\begin{tabular}{cc}
\hline Düz anlam & \multicolumn{1}{c}{ İnsanların kitapçıda bulunması } \\
\hline Gösteren & İnsan \\
\hline Gösterilen & Maoizm \\
\hline Yan anlam & Çin halkının devrime karşı olmayan kitapları okuması \\
Metonimi & Çobanlar \\
\hline $\begin{array}{c}\text { Destansallaştırılan } \\
\text { Söylem }\end{array}$ & Çobanlar Maoizm odaklı yayınları okumayı sever \\
\hline
\end{tabular}

Yan anlam açısından incelendiğinde posterde farklı kültürlere ait giysiler içerisindeki insanların Çin'deki farklı etnik grupların metonimi olarak kullanıldığı ortaya çıkmaktadır. Posterde çobanlar olarak aktarılan insanlar aynı zamanda geçimini hayvancılıkla sağlayan Çinlilerin metonimi olarak da kullanılmaktadır. Posterde resmedilen kişilerin mutlu bir ifade içerisinde kitap aldıklarının aktarılması, insanların okumaktan mutlu olduğu algısını oluşturmaktadır. Posterdeki görsel göstergeler insanların yalnızca kitap aldığını aktarırken, yazılı gösterge ise insanların hangi kitapları aldığını aktarmaktadır. Posterdeki "Çobanlar Maoizm odaklı yayınları okumayı sever" şeklindeki yazılı gösterge doğrudan posterde oluşturulan destansılaştırılan söylemi yansıtmaktadır. Poster, bu şekilde insanlara hangi yayınları okuyacağını telkin etmektedir. Görsel göstergeler ile yazılı gösterge bir bütün olarak

${ }^{14}$ Posterde "Çobanlar Marksizm-Leninizm okumayı sever (牧民爱读马列书)" yazmaktadır. 
ele alındığında Çin halkının Marksizm-Leninizm'i okuduklarında mutluluğa erişeceği algısı oluşturulmaktadır. Böylece insanların Maoizm odaklı yayınları okumaları teşvik edilmektedir.

\section{"Mao" Konulu Propaganda Posteri}

1977 yılına tarihlenen "Mao" konulu propaganda posteri, Mao Wenbiao tarafindan hazırlanmaktadır. Düz anlam açısından incelendiğinde posterin merkezinde ellerinde kitap bulunan birisi kadın üç kişinin resmedildiği görülmektedir. Posterde yer alan erkeklerden birisi üzerinde asker üniformasıyla, diğer iki kişi ise sivil kıyafetler içerisinde resmedilmektedir. Posterde sivil kıyafetler içerisindeki erkeğin elindeki kitabı havaya kaldırdığı görülmektedir. Posterin arka planında da Mao'ya benzetilen bir erkek görselinin etrafinda elinde kitap tutan insanların olduğu aktarılmaktadır.

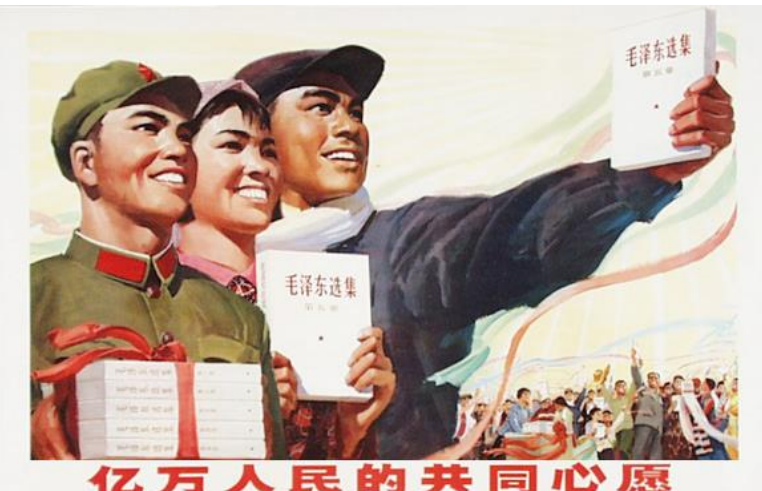

热烈欢吗《毛泽东选焦》第五造出版

Poster 8. "Mao" Konulu Propaganda Posteri ${ }^{15}$ (Kaynak: IISH, 2020).

Tablo 8

"Mao" konulu propaganda posteri

Düz anlam İnsanların kitapları tutması

\begin{tabular}{cc}
\hline Gösteren & İnsan \\
\hline Gösterilen & Maoizm \\
\hline
\end{tabular}

\begin{tabular}{|cc|}
\hline Yan anlam & Çin halkının Mao'nun düşüncelerini okuması \\
\hline Metonimi & Siviller ve asker \\
\hline $\begin{array}{c}\text { Destansallaştırılan } \\
\text { Söylem }\end{array}$ & Çin halkı, Mao'yu ve düşüncelerini sever \\
\hline
\end{tabular}

Yan anlam boyutunda ele alındığında posterde yer alan asker üniformalı kişinin Çin ordusunun, sivil kıyafetli iki kişi ise Çinli sivillerin metonimi olarak kullanıldığı ortaya çıkmaktadır. Posterde mutlu şekilde askerin kitapları elinde tutması, sivillerin ise kitapları göstermesi, Çin'de asker ve sivillerin Mao'nun Seçilmiş Eserleri'ni okuduğu ve okumaktan mutlu olduğu algısını oluşturmaktadır. Böylece "Çin halkı, Mao'yu ve düşüncelerini sever" şeklindeki destansılaştırılan söylem meydana getirilmektedir. Bu destansallaştırılan söylemin

\footnotetext{
${ }^{15}$ Posterde "Bir milyar insanın ortak dileği - Mao Zedong'un Seçilmiş Eserleri'nin beşinci cildinin yayınlanmasını memnuniyetle karş1liyoruz (亿万人民的共同心愿 - 热烈欢呼《毛泽东选集》第五卷出版)" yazmaktadır.
} 
oluşumunda kitaplar birer simge olarak kullanılmakta ve insanların Mao'nun düşüncelerini desteklediği fikri, doğrudan kitaplar üzerinden aktarılmaktadır. Poster, Mao'nun ölümünden ve devrimin sonlanmasından bir yıl sonra yayınlanmaktadır. Buna karşılık ÇKD'nin etkisi doğrudan posterde yansımakta, Mao'nun ölmesine ve devrimin sonlanmasına karşılık hala Mao'nun düşüncelerinin Çin halkı tarafindan beğenildiği mesajı kitlelere verilmeye çalışılmaktadır.

\section{"Tarih" Konulu Propaganda Posteri}

1984 yılında hazırlanan "Tarih" konulu propaganda posteri, Sha De'an ve Li Yang tarafindan yapılmaktadır. Düz anlam boyutunda ele alındığında posterin merkezinde mavi bir kitabı havaya kaldıran bir elin resmedildiği görülmektedir. Posterin arka planında Çin İç Savaşı'nda (veya ÇKD'de) yaşananlara benzer olayları tasvir eden görsellere yer verilmektedir.

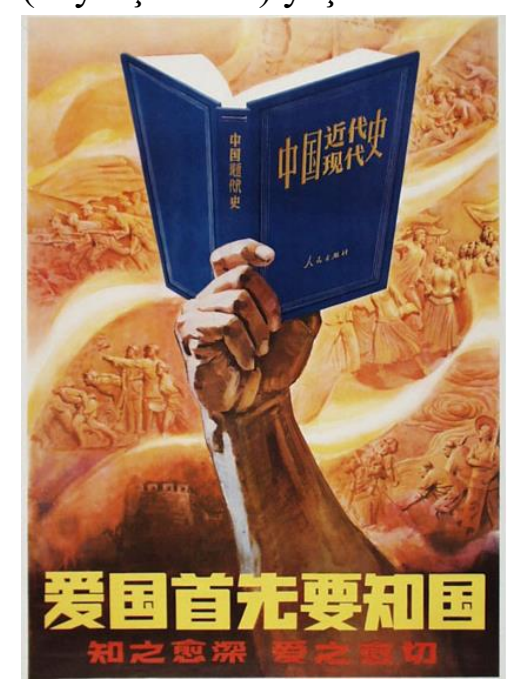

Poster 9. "Tarih" Konulu Propaganda Posteri ${ }^{16}$ (Kaynak: IISH, 2020).

Tablo 9

"Tarih" konulu propaganda posteri

Düz anlam Tarih kitabının gösterilmesi

\begin{tabular}{cc}
\hline Gösteren & Kitap \\
\hline Gösterilen & Çin Komünist Devrimi \\
\hline Yan anlam & Çin halkının devrim tarihini okuması \\
\hline Metonimi & Kitap \\
\hline
\end{tabular}
Destansallaştırılan Çin halkı ülkesini sevmesi için Çin Komünist Devrimi'nin tarihini
Söylem okumalıdır

\footnotetext{
${ }^{16}$ Posterde "Ülkeyi sevmek için önce tarihini bilmek gerekir - bilgi ne kadar derin olursa, sevgi o kadar yoğun olur (爱国首先要知国 - 知之愈深, 爱之㸝切)" yazmaktadir.
} 
Yan anlam açısından incelendiğinde posterde kitlelerin Çin devrim tarihinin okunmasının teşvik edildiği ortaya çıkmaktadır. Kitap, Çin Komünist Devrimi'nin, el ise Çin halkının metonimi olarak kullanılmaktadır. Posterdeki yazılı gösterge, tarih ve sevgi kavramlarını bir bütün olarak sunmakta ve Çin halkının, Çin tarihini kapsamlı olarak öğrenmeleri gerektiğini vurgulamaktadır. Buna karşılık posterin arka planında, Çin tarihi olarak Çin Komünist Devrimi sırasında yaşanan mücadelelere benzer görsellere yer verildiği ortaya çıkmaktadır. Posterde "Çin halkı ülkesini sevmesi için Çin Komünist Devrimi'nin tarihini okumalıdır" şeklindeki destansılaştırılan söylemin hakim kılınmasına çalışılmaktadır. Çin tarihi, Çin Komünist Devrimi ile özdeşleştirilmekte ve tarih boyutunda devrimin daha öncesi arka planda bırakılmaktadır. Bu aşamada poster üzerinden Çin Komünist Devrimi'ne önem atfedilmekte ve insanların devrim sırasında yaşananları öğrenmesi teşvik edilmektedir.

\section{Sonuç}

Çalışma kapsamında incelenen propaganda posterlerinden elde edilen bulgular 1şı̆̆ında devrim yanlılarının doğrudan Maoizm ideolojisi bağlamında Çin halkının okuma alışkanlığını şekillendirmeye çalıştı̆̆ kitlelerin Kırmızı Kitap'ı okumalarının sağlanmasına çalışılmaktadır. Bu aşamada posterlerde Mao'nun Çin halkı tarafından sevildiğine ve desteklendiğine yönelik göstergelere yer verilmekte ve Mao'yu seven insanların da Kırmızı Kitap'ı okuduğu algısı oluşturulmaktadır. Bu şekilde ÇHC'de devrime bağlı kişiler, Mao'yu seven ve onun düşüncelerini okuyan kişiler olarak posterlerde idealize edilmektedir. Posterlerde Çin halkının Kırmızı Kitap’ı okuması durumunda Çin Komünist Devrimi'ni koruyabileceğine, ayrıca ülkede huzur ve barışı sağlayabileceğine yönelik destansallaştırılan söylem kullanılmaktadır. Bu açıdan posterlerde destansallaştırılan söylemler ile genel olarak "Çin halkı Mao'nun düşüncelerini okur" algısının oluşturulmasına çalışılmaktadır.

Posterlerdeki konularda toplumun her kesimine hitap edilmeye çalışılmaktadır. $\mathrm{Bu}$ amaçla propaganda posterlerinde Çinli askerler, işçiler, öğrenciler, çiftçiler, hayvancılıkla uğraşanlar ayrı ayrı Çinli vatandaşların metonimileri şeklinde posterlere konu edilmekte ve Mao’yu ve devrimi konu alan kitapları okumaları teşvik edilmektedir. Posterlerde resmedilen Çin halkının metonimileri, güler yüzlü, devrime bağlı ve Kırmızı Kitap'ı okuyan kişiler olarak sunulmaktadır. Diğer yandan eski gelenekleri ve revizyonizmi ön plana çıkaran yayınlara yönelik nefret söylemi kullanılmakta, bu yolla bu tür yayınlardan Çin halkı uzak tutulmaya çalışılmaktadır. Posterlerde kullanılan görsel ve yazılı göstergelerde, Çin halkının Kırmızı Kitap'ı okumaktan mutlu olduğu yansıtılmakta, bu şekilde Çin genelinde Mao'nun güçlü bir desteğe sahip olduğu ve insanların Maoizm'i öğrenmekten mutlu olduğu algısı oluşturulmaktadır. Posterlerde Kırmızı Kitap'ı okuyan Çinliler devasa boyutta sunulmakta, bu şekilde Mao'nun düşüncelerini okumanın Çin halkını güçlendireceği mesajı verilmektedir. Posterlerde bazı kitapların çöpe atılması, Mao'nun savunduğu ideolojinin öne çıkarılma amacını taşımaktadır. Aynı zamanda saygı gösterilmediği yansıtılan kitapların toplum içerisinde saygın bir yer kazanabilmesi de mümkün olmamaktadır.

Çin Komünist Devrimi ile Mao'nun özdeşleştirildiği devrim sırasında, insanların eski alışkanlıklarını terk etmesi istenmekte, bu şekilde Çin toplumunda Maoizm ideolojisi temelli yeni bir kültürün benimsetilmesi amaçlamaktadır. Maoizm'in benimsetilmesinde ise en önemli araçlardan biri olarak kitaplar ön plana çıkarılmakta ve insanların Mao'nun düşüncelerini 
okuması ve günlük hayatta uygulaması teşvik edilmektedir. Sonuç olarak Mao taraftarı grupların, propaganda posterleri üzerinden oluşturdukları algılarla hem Mao'nun ülke genelindeki iktidarını güçlendirmeye hem de Sovyetler Birliği'nde ortaya çıkan revizyonizmin ÇHC'yi etkisi altına almasını engellemeye çalıştığı ortaya çıkmaktadır. Bu aşamada kitlelerin okuma alışkanlığını geliştirmesi teşvik edilmekte buna karşılık okuma alışkanlığının yalnızca Mao’yu ve devrimi yücelten kitaplar ile sınırlı tutulmasına çalışılmaktadır. Çalışma, ÇKD sırasında propaganda posterleri özelinde Çin halkının okuma alışkanlığının nasıl şekillendirildiğini ortaya çıkarması bakımından önem taşımaktadır. Buna karşılık yalnızca posterler üzerinden incelemenin yapılması çalışmanın temel sınırlılığını oluşturmaktadır. $\mathrm{Bu}$ açıdan gelecek çalışmaların ÇKD sırasında kullanılan farklı kitle iletişim araçları üzerinden okuma alışkanlığının nasıl şekillendirildiğinin, mevcut çalışmadaki bulgularla karşılaştırmalı olarak ele almasının alana katkı sağlayacağı düşünülmektedir. 


\section{Kaynakça}

Ahn, B. J. (1976). Chinese politics and the cultural revolution: Dynamics of policy processes. Seattle, Wash.: University of Washington Press.

Andreas, J. (2002). Battling over political and cultural power during the Chinese cultural revolution. Theory and Society, 31(4), 463-519.

Andreas, J. (2007). The structure of charismatic mobilization: A case study of rebellion during the Chinese cultural revolution. American Sociological Review, 72(3), 434-458. doi: 10.1177/000312240707200306

Arıca, F. A. (2019). Çin Halk Cumhuriyeti'nde Mao Zedong döneminde spor yayıncıllı̆ı üzerine inceleme. TRT Akademi, 4(8), 392-408.

Avc1, Ö. (2018). Propaganda çeşitleri. Karaca, M. ve Çakı, C. (Ed.). Illetişim ve Propaganda içinde (s. 75-114). Konya: Eğitim Yayınevi.

Barnouin, B., ve Yu, C. (1993). Ten years of turbulence: The Chinese cultural revolution. The United Kingdom: Routledge.

Barthes, R. (2015). Bir deneme bir ders: Eiffel Kulesi ve açıllı̧ dersi. (M. Rifat ve S. Rifat, Çev.). 2. Bs. İstanbul: Yap1 Kredi Yayınları.

Barthes, R. (2017). Görüntünün retoriği, sanat ve müzik. (A. Koş ve Ö. Albayrak. Çev.). 2. Bs. İstanbul, Yap1 Kredi Yayınları.

Benewick, R., Chen, X., Clunas, C., ve Gittings, J. (1999). Picturing power in the People's Republic of China: Posters of the cultural revolution. The United States: Rowman \& Littlefield.

Berry, C. (2004). Postsocialist cinema in post-Mao China: The cultural revolution after the cultural revolution. The United Kingdom: Routledge.

Brown, K. (2007). The cultural revolution in Inner Mongolia 1967-1969: The purge of the "Heirs of Genghis Khan”. Asian Affairs, 38(2), 173-187. doi: 10.1080/03068370701349128

Bryant, L. O. (2005). Music, memory, and nostalgia: Collective memories of cultural revolution songs in contemporary China. China Review, 151-175.

Chang, P. H. (1974). The cultural revolution and Chinese higher education: Change and controversy. The Journal of General Education, 26(3), 187-194.

Clark, P. (2008). The Chinese cultural revolution: A history. The United Kingdom: Cambridge University Press.

Croizier, R. C. (2010). Art in turmoil: The Chinese cultural revolution, 1966-76. China: Hong Kong University Press.

Cushing, L., and Tompkins, A. (2007). Chinese posters: Art from the great proletarian cultural revolution. The United States: Chronicle Books.

Çakı, C., ve Dündar, G. (2019). Çin Halk Cumhuriyeti'nde birinci beş yıllık kalkınma planı döneminde (1953-1957) kadınların propaganda posterlerindeki sunumu. Uluslararası Batı Karadeniz Sosyal ve Beşeri Bilimler Dergisi, 3(1), 13-37. Doi: 10.46452/baksoder.557506

Deng, Z., ve Treiman, D. J. (1997). The impact of the cultural revolution on trends in educational attainment in the People's Republic of China. American Journal of Sociology, 103(2), 391-428. 
Çin Halk Cumhuriyeti Kültür Devrimi Sürecinde Okuma Alı̧̧kanlığının Propaganda Posterlerinde Sunumu The Presentation of Reading Habit in the Propaganda Posters Shaped during the Chinese Culture Revolution in the People's Republic of China

Dirlik, A. (1991). Anarchism in the Chinese revolution. The United States: Univ of California Press.

Dittmer, L. (1982). Liu Shao-Chi and the Chinese cultural revolution: The politics of mass criticism (No. 10). The United States: Univ of California Press.

Fiske, J. (2017). İletişim çalışmalarına giriş̧. (S. İrvan, Çev.). 5. Bs. Ankara: Bilim ve Sanat Yayınları.

Gao, M. C. (1994). Maoist discourse and a critique of the present assessments of the cultural revolution. Bulletin of Concerned Asian Scholars, 26(3), 13-32. Doi: 10.1080/14672715.1994.10416158

Gao, C. (2008). The battle for China's past: Mao and the cultural revolution. London: Pluto Press.

Gold, T. B. (1985). After comradeship: Personal relations in China since the cultural revolution. The China Quarterly, 104, 657-675.

Giles, J., Park, A., ve Wang, M. (2019). The great proletarian cultural revolution, disruptions to education, and the returns to schooling in urban China. Economic Development and Cultural Change, 68(1), 131-164.

Gittings, J. (1966). The Chinese army's role in the cultural revolution. Pacific Affairs, 269-289. Doi: $10.2307 / 2754273$

Guiraud, P. (2016). Göstergebilim. (M. Yalçın, Çev.). 3. Bs. Ankara: İmge Kitabevi.

Guoqiang, D., ve Walder, A. G. (2011). Local politics in the Chinese cultural revolution: Nanjing under military control. The Journal of Asian Studies, 70(2), 425-447. doi:10.1017/S0021911811000039

Gülada, M. O., Gazi, M. A., ve Çakı, C. (2019). Nazi propagandasının ulusal seferberlikte idealize ettiği Alman genç kızları: "Das Deutsche Mädel” dergisi üzerine inceleme. Erciyes İletişim Dergisi, 6(2), 1079-1100. Doi: 10.17680/erciyesiletisim.515202

Han, D. (2008). The unknown cultural revolution: Life and change in a Chinese village. New York: NYU Press.

Heberer, T. (2009). The "great proletarian cultural revolution": China's modern trauma. Journal of Modern Chinese History, 3(2), 165-181.doi: 10.1080/17535650903345379

Huang, P. C. (1995). Rural class struggle in the Chinese revolution: Representational and objective realities from the land reform to the cultural revolution. Modern China, 21(1), 105-143. Doi:10.1177/009770049502100105

Huang, Y. (2007). Contemporary Chinese literature: From the cultural revolution to the future. Germany: Springer.

IISH. (2020). "Çin Kültür Devrimi'ne ait posterler". Erişim Adresi: https:// search. socialhistory .org/ Search /Results? \&format\% 3A\%22 Visual+ documents \%22 \&lookfor =China+ poster+ Mao +Tse -Tung

Jian, G., Song, Y., ve Zhou, Y. (2015). Historical dictionary of the Chinese cultural revolution. The United States: Rowman \& Littlefield.

Jin, B., Li, L., ve Rousseau, R. (2004). Long-term influences of interventions in the normal development of science: China and the cultural revolution. Journal of the American Society for Information Science and Technology, 55(6), 544-550. Doi: 10.1002/asi.20010 
Jin, Y., Manning, K. E., ve Chu, L. (2006). Rethinking the 'Iron Girls': Gender and labour during the Chinese cultural revolution. Gender \& History, 18(3), 613-634.

Joffe, E. (1973). The Chinese army after the cultural revolution: The effects of intervention. The China Quarterly, 55, 450-477. Doi: 10.1017/S0305741000009127

Kalkan Kocabay, H. (2008). Tiyatroda göstergebilim. İstanbul: E Yayınları.

Karaca, M., Gazi, M. A. ve Çakı, C. (2020). Kore savaşı ekseninde ABD-Çin iliş̧kilerinin Çin propaganda posterleri üzerinden analizi. MANAS Sosyal Araştırmalar Dergisi, 9(2), 1142-1156. Doi: $10.33206 / \mathrm{mjss} .553010$

Lee, H. Y. (1978). The politics of the Chinese cultural revolution: A case study. (v. 17). The United States: Univ of California Press.

Lester, D. (2005). Suicide and the Chinese cultural revolution. Archives of suicide research, 9(1), 99104. Doi: 10.1080/13811110590512994

Leung, C. B., ve Wang, Y. (2012). Influences of the cultural revolution on Chinese literacy instruction. Leung, C. B. ve Ruan, J. (Ed.). In Perspectives on teaching and learning Chinese literacy in China (s. 49-60). Dordrecht: Springer.

Li, M. (2011). Ideological dilemma: Mao's China and the Sino-Soviet split, 1962-63. Cold War History, 11(3), 387-419. Doi: 10.1080/14682745.2010.498822

Lin, Q. (2013). Lost in transformation? The employment trajectories of China's cultural revolution cohort. The ANNALS of the American Academy of Political and Social Science, 646(1), 172-193. Doi: $10.1177 / 0002716212468689$

Lu, X. (2004). Rhetoric of the Chinese cultural revolution: The impact on Chinese thought, culture, and communication. The United States: Univ of South Carolina Press.

MacFarquhar, R. (1974). The origins of the cultural revolution. (v. 3). London: Oxford University Press.

Marku, Y. (2020). Communist relations in crisis: The end of Soviet-Albanian relations, and the SinoSoviet split, 1960-1961. The International History Review, 42(4), 813-832. Doi: 10.1080/07075332.2019.1620825

McGrath, J. (2010). Cultural revolution model opera films and the realist tradition in Chinese cinema. The Opera Quarterly, 26(2-3), 343-376. Doi: 10.1093/oq/kbq016

Meng, X., ve Gregory, R. G. (2002). The impact of interrupted education on subsequent educational attainment: A cost of the Chinese cultural revolution. Economic Development and Cultural Change, 50(4), 935-959.

Perry, E. (2018). Proletarian power: Shanghai in the cultural revolution. The United Kingdom: Routledge.

Powell, P., ve Wong, J. (1997). Propaganda posters from the Chinese cultural revolution. The Historian, 59(4), 777-793. Doi: 10.1111/j.1540-6563.1997.tb01375.x

Roberts, R. (2004). Positive women characters in the revolutionary model works of the Chinese cultural revolution: An argument against the theory of erasure of gender and sexuality. Asian Studies Review, 28(4), 407-422. Doi: 10.1080/10357820500032487 
Çin Halk Cumhuriyeti Kültür Devrimi Sürecinde Okuma Alışkanlığının Propaganda Posterlerinde Sunumu The Presentation of Reading Habit in the Propaganda Posters Shaped during the Chinese Culture Revolution in the People's Republic of China

Rifat, M. (2013). Açıklamalı göstergebilim sözlüğ̈̈: Kavramlar, yöntemler, kuramcılar, okullar. İstanbul: Türkiye İş Bankası Kültür Yayınları.

Shen, Z., ve Xia, Y. (2011). The great leap forward, the people's commune and the Sino-Soviet split. Journal of Contemporary China, 20(72), 861-880. Doi: 10.1080/10670564.2011.604505

Sığırcı, İ. (2016). Göstergebilim uygulamaları, metinleri, görselleri ve olayları okuma. Ankara: Seçkin Yayinc1lik.

Sobhe, K. (1982). Education in revolution: Is Iran duplicating the Chinese cultural revolution?. Comparative Education, 18(3), 271-280. Doi: 10.1080/0305006820180304

Song, L. (2009). The effect of the cultural revolution on educational homogamy in urban China. Social Forces, 88(1), 257-270. Doi: 10.1353/sof.0.0246

Swetz, F. J. (1973). Chinese education and the great cultural revolution: A search for relevance. Contemporary Education,44(3), 155-160.

Ting, L. H. H. (1981). Chinese libraries during and after the cultural revolution. The Journal of Library History (1974-1987), 16(2), 417-434.

Xie, Y., Jiang, Y., ve Greenman, E. (2008). Did send-down experience benefit youth? A reevaluation of the social consequences of forced urban-rural migration during China's Cultural Revolution. Social science research, 37(2), 686-700. Doi: 10.1016/j.ssresearch.2007.08.002

Xing-Hua, L. (2005). Political representation within the libidinal economy of a pictorial space: A political-semiotic reading of three propaganda posters of the Chinese cultural revolution. Semiotica, 2005(157), 213-232. Doi: 10.1515/semi.2005.2005.157.1-4.213

Xiuyuan, L. (1994). A step toward understanding popular violence in China's cultural revolution. Pacific affairs, 67(4), 533-563. Doi: 10.2307/2759573

Xu, X. (2011). "Chairman Mao's child": Sparkling red star and the construction of children in the Chinese cultural revolution. Children's Literature Association Quarterly, 36(4), 381-409. Doi:10.1353/chg.2011.0046

Yang, G. M., ve Suchan, T. (2009). The cultural revolution and contemporary Chinese art. Art Education, 62(6), 25-32. Doi: 10.1080/00043125.2009.11519042

Walder, A. G. (1994). Collective behavior revisited: Ideology and politics in the Chinese cultural revolution. Rationality and Society, 6(3), 400-421. Doi: 10.1177/1043463194006003007

Wang, Y. X., Xu, L., ve Jonas, J. B. (2013). The effect of the Chinese cultural revolution and great leap forward on the prevalence of myopia. European Journal of Epidemiology, 28(12), 1001-1004. Doi: $10.1007 / \mathrm{s} 10654-013-9858-\mathrm{z}$

Zang, X. (2000). Children of the cultural revolution: Family life and political behavior in Mao's China. The United States: Westview Press.

Zhang, T., ve Schwartz, B. (1997). Confucius and the cultural revolution: A study in collective memory. International Journal of Politics, Culture, and Society, 11(2), 189-212. 
Zhang, J., Liu, P. W., ve Yung, L. (2007). The cultural revolution and returns to schooling in China: Estimates based on twins. Journal of Development Economics, 84(2), 631-639. Doi: 10.1016/j.jdeveco.2006.12.006

Zhouxiang, L. (2016). Sport and politics: The cultural revolution in the Chinese sports ministry, 19661976. The International Journal of the History of Sport, 33(5), 569-585. Doi: 10.1080/09523367.2016.1188082

\section{Summary}

The Chinese Cultural Revolution (CCR), which took place between 1966-1976, had an important political and social impact in the People's Republic of China (PRC). There was an intense propaganda activity against counter-revolutionary revisionist groups, reinforcing Mao's leadership cult during the CCR. At this stage, the art of painting was used effectively in propaganda activities. Some of CCR's most enduring paintings occurred in poster arts and were benefited as propaganda tools. Propaganda art in posters was used as a campaign tool and mass media and served as the leading source of information for people. Numerous posters were produced, spread widely, and ideological messages were delivered to the masses through posters. Posters were hung on walls in public spaces and factories. Posters prepared for propaganda purposes had a great importance for the revolutionaries. The ideological messages of the revolution were tried to be adopted by the masses through the posters. One of these was the ideological messages that shape the direct reading habits of the Chinese people. Through the posters, it was explained which publications the Chinese people should read, which publications they should avoid and it was aimed that people turn to publications glorifying the revolution.

When the literature on CCR was examined, it becomes clear that there are many studies dealing with the revolution from different topics. In this study, it was aimed to explain the relationship between CCR and the shaping of reading habits in China. In this respect, the study tried to reveal the way in which the reading habits were shaped in the propaganda posters used during the CCR in PRC. In addition, it was aimed to explain how Mao's leadership cult was used in shaping the reading habit in the CCR. The study is important as it sheds light on China's recent history and explains the role of the CCR in shaping China's reading habits. In this way, it was aimed to explain how ideological revolutions can have an impact on the reading habits of the masses.

All propaganda posters that had an impact on reading habits during the CCR are the universe of the study. As a result of the extensive research carried out in the study, 30 propaganda posters addressing the subject were obtained from Shanghai Propaganda Posters Art Museum. 8 propaganda posters determined by using the quota sample in 30 propaganda posters were determined as the sample of the study. The propaganda posters determined as samples were analyzed using the semiotics method in the qualitative research methods. The perception that was intended to be constructed through propaganda posters in PRC was examined in the light of the understanding of semiotics of French linguist Roland Barthes. Within the scope of the study, which messages are given and which perceptions were formed in shaping the reading habit in Chinese society through propaganda posters in PRC were discussed through the Signification Model. 
In the light of the findings obtained from the propaganda posters examined within the scope of the study, it was revealed that the supporters of the revolution directly tried to shape the reading habits of the Chinese people within the context of the Maoism ideology. By using Mao's leadership cult propaganda, the masses were tried to read the Red Book. At this stage, the posters included indications that Mao was supported by the Chinese people and the perception that people who supported Mao read the Red Book were formed. In this way, the people of the revolution in the PRC were idealized in posters as those who supported Mao and read his thoughts. In the posters, myths were constructed that if the Chinese people read the Red Book, they could protect the Chinese Communist Revolution and also ensure peace in the country. In this respect, the myths constructed in posters generally tried to form the perception that "the Chinese people read Mao's thoughts".

The subjects in the posters were tried to be addressed to all segments of the society. For this purpose, Chinese soldiers, workers, students, farmers were the subject of the posters in the form of metonymies of different Chinese citizens and they were encouraged to read books on Mao and the revolution in the propaganda posters. The metonymies of the Chinese people on posters were presented as genial, revolutionary, and readers of the Red Book. On the other hand, hate speech was used against the publications regarding old traditions and revisionism, and in this way, the Chinese people were tried to be kept away from such publications. The Chinese reading the Red Book were presented on a huge scale in the posters, giving the message that reading Mao's thoughts would strengthen the Chinese people.

People were asked to abandon their old habits, thus aiming to adopt a new culture based on Maoism ideology in Chinese society during the revolution in which Mao was identified with the Chinese Communist Revolution. Books were highlighted as one of the most important tools in the adoption of Maoism and people were encouraged to read Mao's thoughts and applied them in daily life. As a result, it was revealed that the groups who supported Mao tried to strengthen Mao's power throughout the country and to prevented that revisionism that emerged in the Soviet Union influenced the PRC. At this stage, the masses were encouraged to develop the reading habit, while the reading habit was tried to be limited only to the books that glorified Mao and the revolution. The study was important in terms of revealing how the reading habits of the Chinese people were shaped with the propaganda posters during the CCR. On the other hand, the main limitation of the study was to examine only posters. In this respect, it was thought that future studies will contribute to the field by examining how the reading habits were shaped through the different mass media used during the CCR in comparison with the findings of the present study. 